\title{
Design and Analysis of a Skidder Type Supporter for a Combine Harvester
}

\author{
Kapila Peiris and T. B. Adikarinayake
}

Abstract: This paper describes and analyses the turning of a locally developed combine harvester (capacity 1-1.5 acres/day) propelled and powered by the basic structure (engine-gearbox) of a two wheel tractor in paddy fields as well as on up land. In this case the action of a (weight) supporting simple skidder is used to facilitate the turning with two clutches (existing in the two wheel tractor) instead of introducing a brake system for the traction wheels or a controllable caster wheel which are rather complicated and costly. This skidder while supporting a portion of the weight of the machine provides a method of turning with a high degree of controllability (i.e. with less abrupt changes in the Centre of rotation in turning.) A mathematical model is developed to analyze and optimize the system according to the requirement. The action of a free castor wheel is also compared with the action of the skidder

Keywords: Traction force, rolling resistance, Combine harvester

\section{Introduction}

In almost all propelling machines (vehicles), which use clutches (to connect/disconnect power transmission to the driving wheels or tracks separately) to turn, a braking system is also incorporated to the wheels or tracks to facilitate the turning. The Clutch system with the brake system provides a deterministic method of turning the vehicle, i.e. the operator is able to control the vehicle, as he needs. In some vehicles the clutch system and a handle and/or a controllable Caster wheel is provided to facilitate the turning instead of a braking system, for eg. two wheel tractor. A clutch system alone cannot be accepted as a proper method for turning, because such a system will not always precisely behave according to the requirements of the operator. Once the relevant clutch is operated the Centre of rotation of the vehicle will be determined by the road (surface), load and engine condition (speed, torque etc.). The operator does not have proper control over these.

Cutting and threshing of paddy are labour intensive drudgery processes. Therefore, nowadays, many farmers use imported machines for these operations. These imported machines (capacity 1-1.5 acres/day) cost about Rs.350,000 400,000 and could only be used for cutting and threshing of paddy.

The propelling mechanism of these machines are in built to the system in such a way that it is almost impossible to separate it and use for some other purpose for e.g. as a tractor. Considering these factors NERDC initiated a project to construct the cutting and threshing part (with little structural modifications) of the imported combine harvester locally and design a mechanism to power and propel it by an existing two wheel tractor. At the moment NERDC has developed 3 methods of doing this, viz skidder supported front driven (figure 2), skidder supported reverse driven (figure 1) and track driven. The skidder floats on the residue of the paddy plant in the harvesting. Therefore, friction is low and wear is insignificant.

In the rest of this paper, turning of the skidder supported reverse driven combine harvester will be described and analyzed. In the analysis, frictional resistance of the supporting skidder and traction force will be considered as the main parameters influencing the turning action.
Eng. Kapila Peiris, B.Sc.. Eng, M.phil (Agriculture Engineering). M.A. (Buddhist Studies), MIE (SL), C.Eng.(SL). Mechanical Engineer, NERD Centre

Eng. T. B. Adikarinayake, M.Sr, MEng, PhD,

MIE (SL),MIAgrE, C.Eng(UK). Head, Agriculture and Post Harvest Techology Department, NERD Centre 


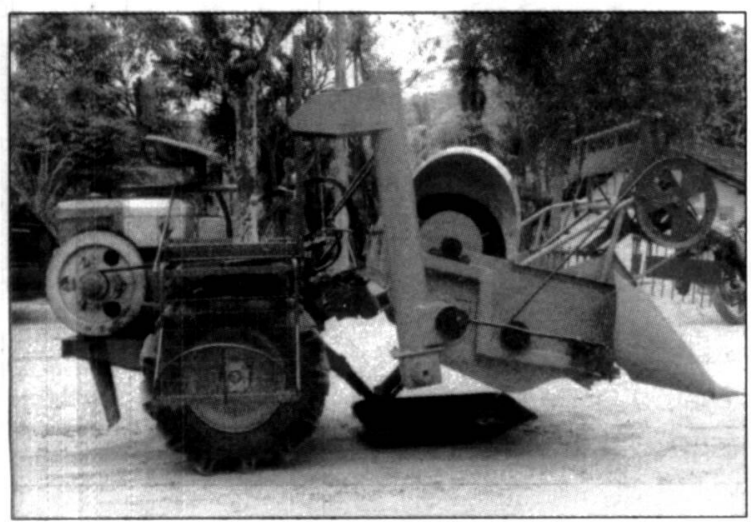

Figure 1: Skidder supported reverse driven

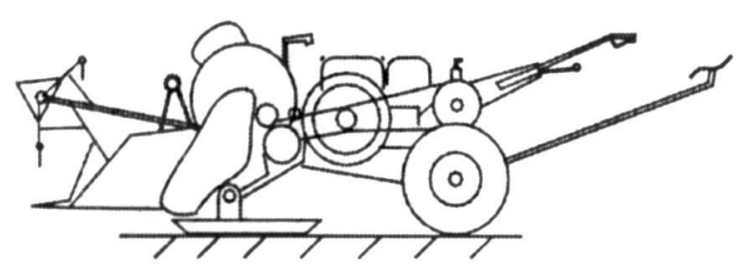

Figure 2: Skidder supported front driven

\section{Objectives of the Project \& Analysis}

To study the possibility of using a simple skidder supporter with two clutch operated traction wheels to facilitate the turning of a two wheel tractor driven combine harvester in paddy fields instead of a brake system for traction wheels, or a controllable castor wheel.

To develop a method (mathematical model) to optimize the relevant parameters in order to achieve a proper turning action (center of rotation) in a particular field.

\section{Rolling Resistance}

Rolling resistance (RR) is created in pneumatic tyres due to the deflection of tyre as well as soil under the contact patch. A model has been developed by Wismer \& Luth 1974 to predict rolling resistance in the field.

$$
R R=W\left[\frac{1.2}{C_{n}}+0.04\right]
$$

$W=$ Vertical load on tyre

$C_{n}=$ Ci.b.d

$C_{i}=$ Cone Index

$b=$ Width of tyre

$d=$ Overall diameter of tyre.

\section{Determiítion of Rolling Resistance}

Due to non-homogeneity of the surface in the paddy field, determination of Cone Index ( $C$ i was difficult. Hence the rolling resistance characteristics of the traction wheels (pneumatic) of the combine harvester was determined by measuring the force required to drag a loaded cart fixed with similar tyres and with similar inflation pressure in the relevant paddy field (figure 3 ) and results are given in figure 4 . A linear regression was performed to obtain the relation between load and rolling resistance.

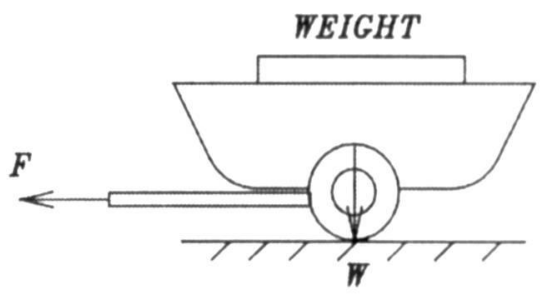

Figure 3: Measuring rolling resistance

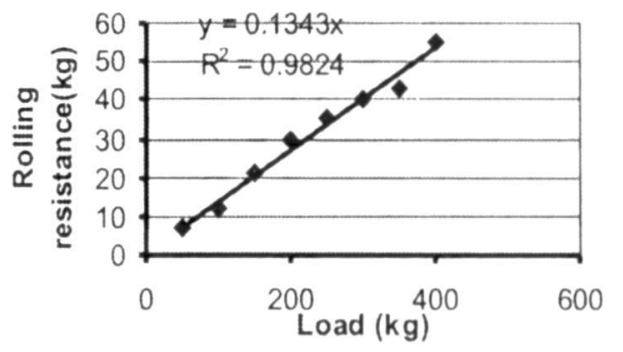

Figure 4: Relationship between RR and Load

\section{Frictional Resistance on the Skidder}

Frictional resistance on the skidder was also determined experimentally (in the paddy field) by a similar method (figure 5) as described above in the determination of rolling resistance and results are given in figure 6 .

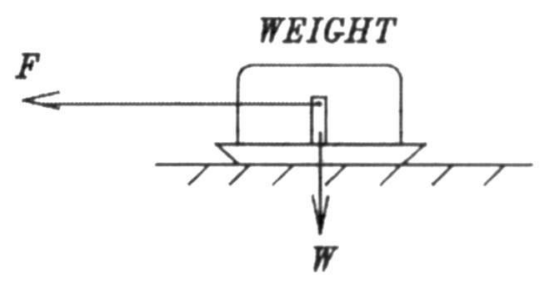

Figure 5: Measuring frictional resistance 


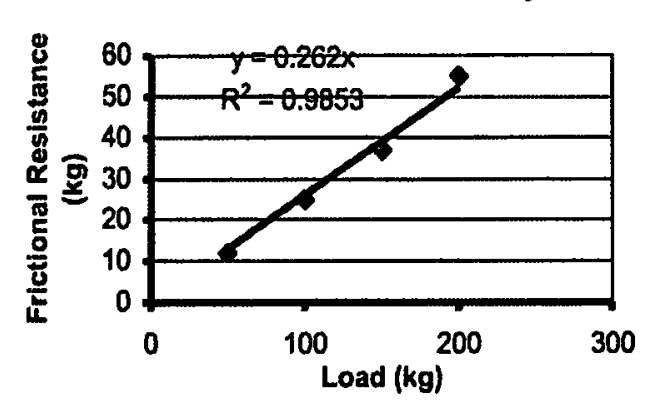

Figure 6 : Relationship between frictional resistance and load

\section{Analyzing the Turning with Skidder (Modeling The System)}

With reference to figures 7 and 8 :

A - Wheel disengaged from power line. (by operating the left clutch) .

B - tractive wheel.

F - Rolling resistance on wheel " $A$ "

$T$ - Net traction force on wheel " $B$ " (traction force - rolling resistance)

$P$ - side force on both wheels

$R$ - Frictional resistance on skidder

$\mathrm{O}_{1}$ - Centre of rotation

C - Distance to the Centre of rotation from the Centre point of two wheels

$\mathrm{W}=$ total weight (with operator and combine harvester part)

$w=$ Weight of combine harvester

$R_{1}=$ Reaction on skidder

$\mathrm{g}=$ Distance between tractor axle and centre of gravity of combine harvester

$\mathrm{a}=$ Half distance between traction wheel

b = Distance between center of skidder and axle.

$\mathrm{m}_{\mathrm{R}}=$ Coefficient of rolling resistance of reaction wheels

$\mathrm{m}_{\mathrm{s}}=$ Coefficient of friction of skidder

$T_{1}=$ Traction required on one traction wheel when moving straight

$\mathrm{T}_{2}=$-Traction required on the traction wheel when turning

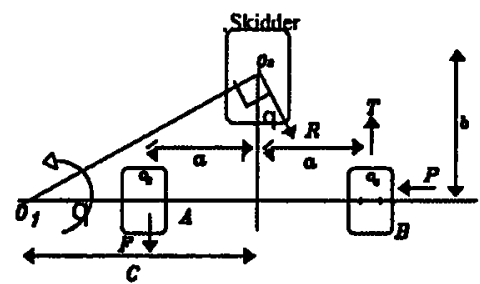

Figure 7: Forces on horizontal plane

\subsection{Assumptions}

1. Frictional resistance on skidder acts perpendicular to $\mathrm{O}_{1} \mathrm{O}_{3}$ at $\mathrm{O}_{3}$

2. Couples acting on wheels (in horizontal plane) from ground due to their turning about the vertical axis through the Centre are neglected.

3. Sinkage of wheel is neglected

4. Tractor part is balanced about wheel axle

5. Effect of inertia is neglected at low speed propulsion $(2-3 \mathrm{~km})$

6. Tractive force on wheel $B$ is adequate to turn

7. The surface is levelled

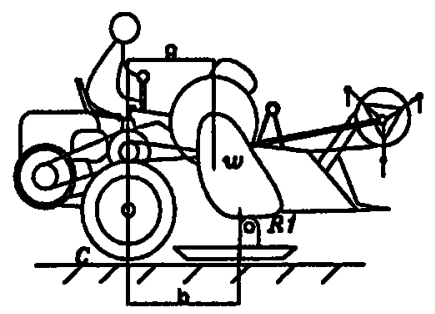

Figure 8: Forces on vertical plane

Considering moments about contact patch $\mathrm{C}$ (Figure. 8)

$g w=b R_{1}$

$\therefore \quad R_{1}=\frac{g w}{b} \cdot m_{s}$

$F=\left[W-\frac{g w}{b}\right] \frac{\mathrm{m}_{\mathrm{R}}}{2}$

Considering moments about $\mathrm{O}_{4}$ (Figure.7)

$m_{R} 2 \mathrm{a}\left[W-\frac{g \mathrm{w}}{b}\right] \frac{1}{2}+\mathrm{a} \frac{\mathrm{gw}}{\mathrm{b}} \cdot m_{s} \cos \theta-b \frac{\mathrm{gw}}{\mathrm{b}} \cdot \mathrm{m}_{s} \sin \theta=0$

Let $a / b=K$,

$a W m_{R}-K g w m_{R}+K g w m_{s} \cos \theta-g w m_{s} \sin \theta=0$

$K g w\left(m_{s} \cos \theta-m_{R}\right)=g w m_{s} \sin \theta-a W m_{R}$

$K=\frac{a g m_{s} \sin \theta-a W m_{\mathrm{R}}}{g w\left(m_{s} \cos \theta-m_{R}\right)}=\frac{a}{b}$

$b=\frac{a g w\left(m_{s} \cos \theta-m_{R}\right)}{g w m_{s} \sin \theta-a W m_{R}}$

$c=\frac{a g w\left(m_{s} \cos \theta-m_{R}\right) \cot \theta}{g w m_{s} \sin \theta-a W m_{R}}$

Considering force balance in figure 8 .

$T_{1}=\frac{\left(m_{s}-m_{R}\right) g W / b+m_{R} W}{2}$

Considering force balance in forward direction in figure 7

$T_{2}=m_{R}\left[W-\frac{g w}{b}\right]+\frac{g w}{b} m_{s} \cos \theta$ 


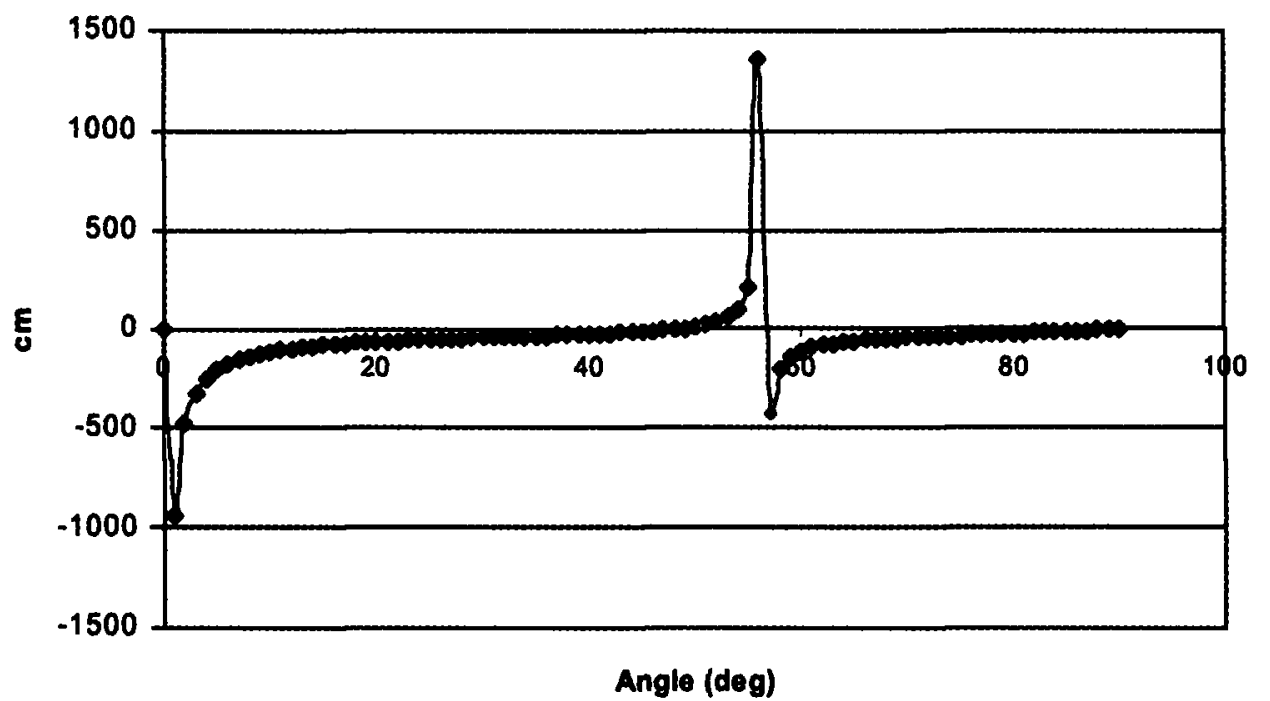

Figure 8: Relationship between " $c$ " and $\theta$

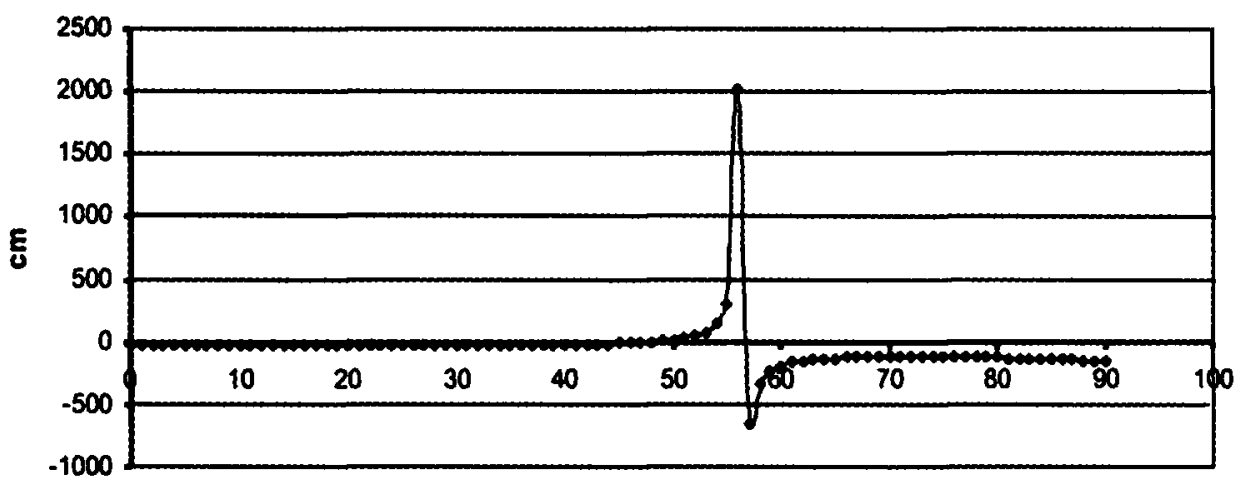

Angle (deg)

Figure 9: Relationship between " $\mathrm{b}$ " and $\theta$

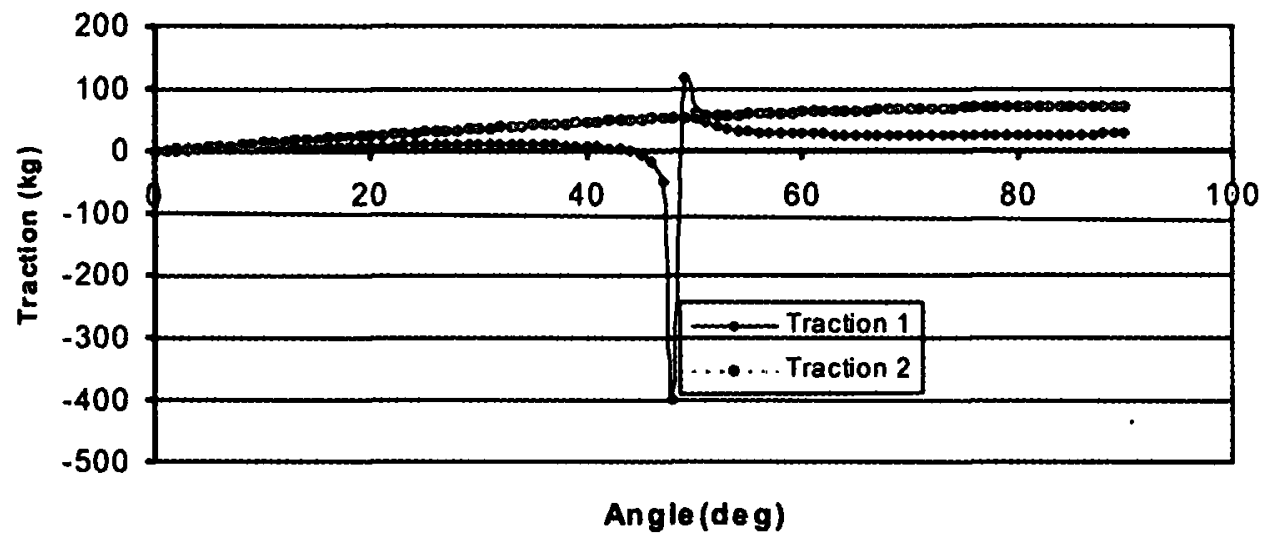

Figure 10: Relationship between $T_{1}, T_{2}$ and $\theta$ 
From equation 1 and 2 it is clear that when $a, b, g$, $m_{s}$ and $m_{R}$ are fixed $c$ is fixed.

Therefore unlike with a caster wheel, the skidder which provides a constant resistive force independent of direction with the rolling resistance of traction wheels provides a fixed center of turning.

Substituting actual values

$W=300 \mathrm{~kg}$ (with operator)

$\mathrm{g}=77 \mathrm{~cm}$

$w=125 \mathrm{~kg}$.

$\mathrm{m}_{\mathrm{s}}=0.26$ (figure 6)

$\mathrm{m}_{\mathrm{R}}=0.13$ (figure 4)

Figures $8,9,10$ shows the graphs of $c, b$ and $T_{1}$ \& $T_{2} V s \theta$ respectively.

Reaction on traction wheels $=w-w g / b>0$

$$
\begin{aligned}
& b>g w / w \\
& b>32 \mathrm{~cm}
\end{aligned}
$$

From figures 8 and 9

If $b>32 \mathrm{~cm}$, then $\theta>510$

$$
C>25 \mathrm{~cm}
$$

From figure 10, it is clear that when $\theta>510$ $\mathrm{T}_{2}>\mathrm{T}_{1}$

When $b=32 \mathrm{~cm}$ Traction is zero (reaction is zero).

Therefore " $b$ " was increased from $32 \mathrm{~cm}$ until enough traction was built up for turning $\left(T_{2}\right)$ in the same field and it was found that at $b=60 \mathrm{~cm}$ the traction (for turning) was adecuate. Therefore ' $b$ ' was fixed at $b=60 \mathrm{~cm}$, for this position $C=60$ $\mathrm{cm}$ (from figure 8) which is the minimum radius of turning for the given combine harvester in the given field. Measured $C$ values for turning at randomly selected 5 places in the field are shown in table 1.

Table 1:

Tuming centers at randomly selected places

\begin{tabular}{|l|c|c|c|c|c|}
\hline $\begin{array}{l}\text { Place } \\
\text { No. }\end{array}$ & 1 & 2 & 3 & 4 & 5 \\
\hline $\begin{array}{l}\text { C } \\
\text { value } \\
\text { (cm) }\end{array}$ & 65 & 60 & 62 & 58 & 55 \\
\hline
\end{tabular}

\section{Results \& Discussion}

This analysis provides a method to determine the relevant parameters, mainly the distances $a, b, g$ of the machine with the skidder in order to achieve a suitable turning radius in a particular field. Also, this could be extended to optimize the overall performance of the machine related to the field, i.e. optimizing the system considering traction performance, fuel consumption, turning, etc. as a whole. In the above analysis the parameter " $b$ ", which was the only variable, was determined to get the minimum possible turning radius. If the minimizing of turning radius was not much important and reducing the traction force was much more important the parameter " $b$ " would have been increased accordingly. According to the test results, the predicted distances to Centre of rotation from centerline are quite close to the actual values. Reasons for the discrepancies between theoretical and practical values could be explained as follows. The above model to predict the center of rotation was developed assuming a levelled surface. But in a paddy field due to pits and lumps the plane generated by three supporting points (viz. skidder \& tractor wheels) is not always horizontal. Therefore, gravity influence to the turning action and also $\mathrm{ms}$ and $\mathrm{mr}$ may vary slightly from place to place in the field. Hence the center of rotation will differ from the predicted. With this skidder, when a particular clutch is operated the machine will turn about a point, which is determined by the values $\mathrm{ms}$ and $\mathrm{mr}$ and will depend on the condition of the field. Therefore, for a particular field the turning will be almost similar. Also, the skidder facilitates to move the machine across bunds of about $250 \mathrm{~mm}$ in the field. In soft paddy fields, when the traction wheels sink to about $75 \mathrm{~mm}-125 \mathrm{~mm}$ the couple active upon the traction wheels by the field tends to reduce the reaction on the skidder. Hence the resistance force on the skidder is reduced. Due to this reduction as well as increase in rolling resistance, the center of rotation moves almost into the contact patch of the inner wheel making the radius of rotation as small as possible.

In soft paddy fields, when the skidder was replaced by a free caster wheel, controlling was not satisfactory due to the sinking of the caster wheel. Also, due to drastic changes of the force on the caster wheel (when compared to skidder) from obstacles in the field in turning, the center 
of rotation varies significantly. In dry (hard) paddy fields the caster wheel did not give satisfactory controllability in turning due to erratic changes of the direction due to lumps and pits in the field. The skidder does not respond to these lumps and pits as a free caster wheel.

On roads, the frictional resistance of the skidder was too high and wearing of the skidder was significant. Although the caster wheel eliminates these shortcomings, the controllability was not satisfactory compared to the skidder. The forces created by obstacles on traction wheels as well as on the caster wheel change the center of rotation significantly. Once the free castor wheel is turned to a direction due to obstacles, it takes a transient period to come back, which leads to uncontrollability. Also when the harvester is operating on tilted surfaces, the axis of rotation of caster wheel is not parallel to the gravity plant. In this situation gravity will influence turning confusing the operator. Also, when coming down on tilted surfaces the engine of the tractor might act as a brake. In such situations the turning will be totally the other way round, i.e. if the operator operates the right side clutch the machine will turn to the left.

The main advantages of the skidder, compared with the caster wheel (mainly in a paddy field) is that the skidder provides a constant resistive force independent of direction of movement. This is due to the size and shape of the skidder. This constant force provides a fixed center of rotation and fixed center of rotation provides good controllability in turning.

Therefore, a skidder type support will provide a simple method of turning a two wheel driven (clutch operated) three point supported (two wheels and skidder) combine harvester in a paddy field as well as on grass lands.

\section{References}

1. Sakai J, "Two-wheel tractor Engineering" Shinnorinsha Co., Ltd., Tokyo, 1999.

2. Koolen H. J., H Knipers, "Dynamic Analysis of Rolling element, Agriculture Soil Mechanics", Springer Verlag Berlin Heidelbing New York. Page 120, 1983

3. Pieris $W K R$ "Design and construction of a Dual Purpose Two Wheeled Tractor Gear Box and Steering Wheel, Attachment" Thesis of Degree of Master of Philosophy University of Peradeniya, 2004

\section{Acknowledgements}

We would like to thank Eng. Mahinsasa Narayana for his invaluable assistance to edit this paper. 